\title{
Reinhart Koselleck e a análise das metáforas: sobre as possibilidades para além do conceitual
}

\begin{abstract}
Resumo
Este artigo explora - em diálogo com estudos recentes no âmbito da teoria da história e história intelectual, especialmente seguindo as perspectivas de Hans Ulrich Gumbrecht e Elías Palti -, os limites da história dos conceitos (Begriffsgeschichte) e a possibilidade da sua dinamização frente à abertura para a análise das metáforas. Pretendo compreender a especificidade da importância conferida por Reinhart Koselleck à análise das "metáforas espaciais" em seu projeto intelectual, diferenciando as perspectivas do autor das de Hans Blumenberg. Evidencio como Koselleck articulou a importância das metáforas em face à centralidade conferida à sua teoria da modernização. Por fim, a intenção será matizar a relevância das contribuições de Koselleck para os estudos historiográficos perante a necessidade da abertura para desafios que não se limitem ao conceitual, como colocado em destaque pela bibliografia especializada contemporânea.
\end{abstract}

Palavras-chave: História dos Conceitos. Teoria da Modernização. Teoria da Não Conceitualidade. Linguagem. Metáforas.

\section{André da Silva Ramos}

Doutor em História pela Universidade Federal de Ouro Preto (UFOP). Professor Substituto de

Teoria e Metodologia da História da Universidade Federal dos Vales do Jequitinhonha e Mucuri (UFVJM).

Diamantina - MG - BRASIL

andramos7@gmail.com orcid.org/0000-0002-4624-4524

\section{Para citar este artigo:}

RAMOS, André da Silva. Reinhart Koselleck e a análise das metáforas: sobre as

possibilidades para além do conceitual. Tempo e Argumento, Florianópolis, v. 11, n. 26, p. 431 - 455, jan./abr. 2019. 


\title{
Reinhart Koselleck and the analyses of metaphors: on possibilities beyond the conceptual
}

\begin{abstract}
This article intends to explore in dialogue with current studies in the realm of the Theory of History and Intellectual History the limits of the History of Concepts (Begriffsgeschichte) and the possibility of its enrichment through the opening for the analyses of metaphors, following the approaches of Hans Ulrich Gumbrecht and Elías Palti. It intends to understand the specificity of the importance conferred by Reinhart Koselleck to the analyses of "spatial metaphors" in his intellectual project, differentiating this approach from Hans Blumenberg's perspectives. The article analyses Koselleck approaches to the metaphors' importance considering the centrality that he gives to his theory of modernization. Furthermore, the article shows the relevance of Koselleck's conceptual approach to the historiographic studies regarding the necessity of a theoretical opening for the non-conceptual challenge, as it is stressed by the contemporary specialized bibliography.
\end{abstract}

Keywords: Conceptual History. Theory of Modernization. Theory of Non-Conceptuality. Language. Metaphors.

Agradeço ao Professor Valdei Lopes de Araujo pela orientação e à CAPES pelo financiamento da pesquisa de Doutorado. Tive a oportunidade de realizar estágio de Doutorado sanduíche na Stanford University, sob a orientação do Professor Hans Ulrich Gumbrecht, e na Wesleyan University, sob a orientação do Professor Ethan Kleinberg, com os quais pude discutir questões abordadas neste texto. Agradeço aos respectivos professores pela orientação e à Fulbright/CAPES pelo financiamento dos estágios de pesquisa, que aconteceram durante $\mathrm{o}$ ano acadêmico 2015/2016. Agradeço também à Thamara de Oliveira Rodrigues, que leu a primeira versão deste texto e ao Professor Marcelo Rangel, cujo diálogo foi fundamental para o meu desenvolvimento acadêmico durante os anos de pós-graduação na Universidade Federal de Ouro Preto (UFOP). 


\section{Introdução}

A importância da história dos conceitos (Begriffsgeschichte), particularmente as contribuições de Reinhart Koselleck para os estudos historiográficos, é de fato incontornável. Essa afirmação pode ser facilmente comprovada ao nos depararmos com a fortuna crítica contemporânea que confere centralidade à obra do historiador alemão. Estudos recentes no âmbito da teoria da história, história intelectual e história da historiografia ressaltam o quão importante são as formulações de Koselleck no que tange à compreensão da coexistência sincrônica de múltiplas temporalidades históricas (FERES JR; JASMIN, 2006; ARAUJO, 2008b, 2011b, 2013; JORDHEIM, 2012; BEVERNAGE; LORENZ, 2013; KLEINBERG, 2012, 2017; KLEINBERG; RAMOS, 2017). A rede Iberconceptos também demonstra a pujança do legado deixado por Koselleck para a história dos conceitos, ao se propor compreender, a partir de uma perspectiva comparada, a modernização dos vocabulários políticos no mundo ibero-americano (SEBASTIÁN, 2009a, 2014). No âmbito da história da historiografia brasileira, deve ser ressaltada a importância do diálogo com a obra do historiador alemão para a compreensão das complexidades que enredam o processo de modernização da experiência e a constituição de múltiplos, conflitantes e interconectados projetos nacionais no século XIX (ARAUJO, 2008a; RANGEL, 2011; RAMOS, 2013, 2018; RODRIGUES, 2014; RAMOS; RODRIGUES, 2014; ARAUJO; RAMOS, 2015, 2018).

Todavia, atualmente no âmbito dos estudos historiográficos, tem se ampliado a demanda pelo debate sobre as dimensões não conceituais que se relacionam com as possibilidades de efetivação de qualquer enunciação. Podemos destacar as discussões em torno do que Ethan Kleinberg denominou de "paradigma da presença", que partem do pressuposto que a linguagem e a materialidade do passado podem evocar experiências estéticas para além da transmissão de sentido (KLEINBERG; RAMOS, 2017). Esse debate foi sistematizado no livro Presence: Philosophy, History and Cultural Theory for The TwentyFirst Century (GOSH; KLEINBERG, 2013), assim como em dossiês nos importantes periódicos History and Theory (2006) e Storia della Storiografia (2009). A fortuna crítica desse debate no Brasil constitui-se em torno da recepção da obra de Hans Ulrich Gumbrecht (ARAUJO, 2006) e do desenvolvimento das suas proposições no tocante à 
abordagem da linguagem em estudos no campo da história da historiografia. Especialmente nos estudos realizados no âmbito da história da historiografia brasileira, podemos destacar o esforço de complexificação do legado da história dos conceitos, tendo em vista a realização de análises que visam compreender tanto o processo de modernização da experiência e suas fissuras, quanto o potencial da linguagem e outras tecnologias de representação em evocar fenômenos estéticos, circunscrevendo a complementariedade e interpenetrações dessas dimensões da realidade (ARAUJO, 2011a; RANGEL, 2013, 2014; RAMOS, 2013, 2018, RODRIGUES, 2014).

Autores como Hans Ulrich Gumbrecht e Elías Palti, em reflexões recentes, têm dado vazão a este campo de problemas relativo à dinamização do legado da história dos conceitos. Principalmente o primeiro, que em face à possibilidade da linguagem instaurar fenômenos estéticos, dedica-se a pensar como os corpos são tocados pelo que o autor categoriza como "efeitos de presença" e "climas" (stimmungen) (GUMBRECHT, 2010; GUMBRECHT, 2012). Por sua vez, Palti, em diálogo com Hans Blumenberg, se propõe a pensar como a história intelectual pode explicar os motivos que subjazem as mudanças conceituais, remetendo-se dessa forma a dimensões não conceituais do real, ou seja, às metáforas (PALTI, 2010, 2011).

Tendo em vista a limitação da tradição da história dos conceitos (Begriffsgeschichte) em relação ao simbólico, os autores apontam quão promissores poderiam ser os diálogos dos pesquisadores contemporâneos ligados a esse campo de investigação com as reflexões de Hans Blumenberg sobre as metáforas. Ambos os autores apontam que Koselleck se afastou das reflexões sobre as dimensões não conceituais da realidade devido à dependência teórica da história dos conceitos com relação à história social, o que impossibilitou a incorporação da análise das metáforas. Por sua vez, Javier Fernández Sebastián conferiu relativa importância à abertura para a análise das metáforas no âmbito da história dos conceitos, contudo, tais proposições se apresentam fortemente conectadas com as de Koselleck relativas à abordagem das “metáforas espaciais" (SEBASTIÁN, 2009b). Dessa forma, pretendo compreender a especificidade da importância conferida por Koselleck à análise das “metáforas espaciais” 
em seu projeto intelectual, diferenciando as perspectivas do autor das de Hans Blumenberg.

Portanto, neste artigo seguirei os argumentos de Gumbrecht e Palti em 1) no que diz respeito à dependência da história dos conceitos com relação à história social e 2) como isso se liga ao afastamento da tradição da história dos conceitos às proposições teóricas de Blumenberg. Posteriormente, analisarei como Koselleck incorporou a reflexão das "metáforas espaciais" à sua teoria da modernização. Exploro como o historiador centrou esforços em demonstrar como as "metáforas espaciais" são decisivas ao condicionarem múltiplas possibilidades de sedimentação conceitual. Nesse sentido, analiso como Koselleck compreendeu as "metáforas espaciais" como uma dimensão estruturante da linguagem, porém, afastou-se de compreensões legadas por Blumenberg que visaram demonstrar como as metáforas podem resistir ou até mesmo suspender a atribuição de sentido. Dessa forma, o objetivo será matizar a relevância das contribuições de Koselleck para os estudos historiográficos perante a necessidade da abertura para as experiências daquilo que o sentido não pode transmitir, como problematizado pela bibliografia especializada contemporânea.

\section{Tensões entre a história dos conceitos e a história social}

Hans Ulrich Gumbrecht contribuiu com a escrita de inúmeros verbetes para dicionários dedicados à descrição de conceitos filosóficos, históricos e estéticos ao longo da sua carreira. Para os Conceitos históricos básicos - Léxico histórico da linguagem político-social da Alemanha, por exemplo, organizado por Reinhart Koselleck, Werner Conze e Otto Brunner, Gumbrecht contribuiu com os verbetes Moderno e Pós-Moderno. 0 autor inicia a coletânea de ensaios Graciosidade e Estagnação com o texto Pirâmides do espírito, no qual explica o entusiasmo que motivou o empreendimento dos dicionários ao longo das décadas de 60, 70 e 80 e, simultaneamente, descreve o esmorecimento contemporâneo com as perspectivas teórico-metodológicas da história dos conceitos (GUMBRECHT, 2012). 
Gumbrecht não nega que o entusiasmo dos seus contemporâneos com relação aos dicionários era o mesmo que o moveu a pesquisar arduamente para a escrita dos seus verbetes. Contudo, retrospectivamente, o autor propôs-se explicar como as fragilidades teóricas do projeto foram decisivas para o esmorecimento da história dos conceitos nas últimas décadas. Gumbrecht aponta que Koselleck e outros historiadores que participaram do Léxico "travavam uma dura batalha em torno da diferença entre "história conceitual' e 'história factual”, sendo que para "aqueles que insistiam na referência à esfera da 'história factual', o status da 'história conceitual' devia parecer ontologicamente secundário". Apesar de Koselleck não querer "fazer concessões ao primado da "história factual", não "estava disposto a ir tão longe quanto seu contemporâneo Michel Foucault, que havia de facto excluído do campo da sua pesquisa todos os fenômenos não discursivos" (GUMBRECHT, 2012, p. 33). Gumbrecht aponta uma indecisão no projeto de Koselleck, que por um lado "optava por uma posição na qual a história dos conceitos aparecia como uma instância intermediária a caminho de uma história factual”, e por outro lado reivindicava "uma pretensão de totalidade a favor da história conceitual" (GUMBRECHT, 2012, p. 33-34). Para o autor, essa flutuação teórica foi decisiva para que a história dos conceitos obtivesse sucesso institucional a não ser tão impactada pelo "trauma da perda do mundo concreto, que acompanha, como uma sombra escura, as ciências humanas desde a sua fundamentação hermenêutica por Wilhelm Dilthey" (GUMBRECHT, 2012, p. 47). Sendo assim, Gumbrecht caracteriza um aspecto da inconsistência teórica da história dos conceitos:

[...] a primeira dimensão especial da história dos conceitos que permaneceu totalmente oculta, inclusive aos próprios participantes, é a institucionalização de uma indecisão em relação ao problema da referência ao mundo da linguagem. Em nenhum momento o assim chamado "construtivismo" ou as posições filosoficamente mais respeitáveis do "linguistic turn" tornaram-se o fundamento único ou o meio de entendimento dominante daqueles que se dedicavam à história dos conceitos. De uma perspectiva oposta, nunca se abriu mão inteiramente da pretensão de tornar plausíveis, mediante os conceitos investigados, zonas de realidade extralinguísticas, mas acessíveis à linguagem, seja preliminarmente ou sob a forma de vestígios. Em nenhum momento um condicionamento situacional vinculado à linguagem, um relativismo ou perspectivismo das visões do mundo estabeleceram-se como premissas "resignadas", por assim dizer, da história dos conceitos. (GUMBRECHT, 2012, p. 46-47) 
Elías Palti se aproxima do diagnóstico de Gumbrecht no texto From ideas to concepts to metaphors ao discutir a incongruência dos conceitos, ou seja, o fato dos conceitos serem sempre polissêmicos. Palti expõe, seguindo Koselleck, que a pluralidade de significados e experiências transportadas diacronicamente pelos conceitos constitui a sua característica fundamental. Porém, o autor coloca em destaque que Koselleck não explica quais estruturas formais invadem os universos simbólicos e os reconfiguram, impossibilitando o encerramento lógico dos sistemas conceituais, abrindo-os à temporalidade. Ou seja, o autor enfatiza que Koselleck não teria respondido o que fazem os conceitos mudarem. Para Palti, tal explicação não foi possível devido à compreensão de Koselleck de que a história dos conceitos nunca excederia completamente a história social. Por um lado, a história dos conceitos teria autonomia por transportar experiências e expectativas diacronicamente, efetivar a simultaneidade do não simultâneo, por outro, a ação social sempre poderia ultrapassar o que está sedimentado na linguagem. Nesse sentido, o autor escreve:

[... ] enquanto a história conceitual excede a história social na medida em que articula teias conceituais significativas de longo prazo, para Koselleck, a primeira é ao mesmo tempo deficiente com relação à segunda, nunca a esgotando. Fatos sociais, séries extralinguísticas, ultrapassam a linguagem na medida em que a performance de uma ação sempre excede sua mera enunciação ou sua representação simbólica. Isso explica porque conceitos, qua cristalizações de experiências históricas, podem possivelmente ser alterados; isto é, como os eventos acabam frustrando as expectativas existenciais depositadas nos conceitos, ganhando deste modo novos sentidos. Dessa forma, nós podemos falar de um duplo excesso na relação entre história conceitual e história social, entre séries linguísticas e extralinguísticas. (PALTI, 2010, p. 198)

Ao apontar a limitação teórica da história dos conceitos em face à sua relação com a história social, Palti questiona quais estruturas formais seriam de fato decisivas para a efetivação das possibilidades de mudanças e permanências conceituais. A intenção de Palti é ampliar o entendimento sobre esta "esfera que resiste a simbolização em relação às categorias disponíveis em uma dada linguagem, deslocando-a". O autor se questiona sobre a "natureza ontológica" dessa dimensão que não é passível de ser plenamente investida de sentido, mas invade o universo simbólico e força sua reconfiguração (PALTI, 
2010, p. 198). Dessa forma, Palti não se questiona apenas sobre como os conceitos mudam, mas como o sistema simbólico do qual ele faz parte reconstitui-se com a pluralização de significados. Nesse sentido, o autor pretende compreender como a história intelectual pode analisar a lógica das mudanças dos sistemas simbólicos, ou seja, pensar as relações de continuidade e descontinuidade. Segundo Palti, Koselleck não respondeu essa questão, pois ela jaz em um "nível mais primitivo da realidade simbólica: não mais no plano dos conceitos individuais, mas em estruturas formais que determinam as condições de sua enunciação" (PALTI, 2010, p. 198).

Apesar de Gumbrecht e Palti apontarem os limites teóricos da história dos conceitos, ambos afirmam a grande relevância da obra de Koselleck. Gumbrecht argumenta sobre a aceitação massiva da teoria da modernização de Koselleck em meio a historiadores renomados que participaram do Léxico. Palti, por sua vez, expõe como Koselleck teria sido capaz de ir além das limitações da tradicional história das ideias, compreendida como responsável por reduzir as performances dos textos a unidades de sentido essenciais, subsumindo a historicidade dos mesmos. Ao apontar as venturas e desventuras da história dos conceitos, ambos os autores descortinaram uma alternativa que possibilitaria a revitalização contemporânea do seu legado. Em uníssono, Gumbrecht e Palti argumentam sobre a importância do diálogo com as proposições teóricas de Hans Blumenberg.

\section{Do veto a Hans Blumenberg à possibilidade de expansão dos horizontes}

A partir da análise dos projetos do Dicionário histórico de filosofia, dos Conceitos históricos básicos e dos Conceitos estéticos básicos, Gumbrecht explica o surgimento do entusiasmo pelas perspectivas teórico-metodológicas da história dos conceitos e seu posterior esmorecimento. O autor vincula o entusiasmo inicial às esperanças dos participantes dos dicionários em "[...] documentar historicamente o sentido e os mundos do passado - ou seja, o seu 'espírito' - a partir de conceitos centrais e, desse modo, transformá-los em instrumentos de diálogo voltado para a reflexão sistemática" (GUMBRECHT, 2012, p. 16). Joachim Ritter, no prefácio ao primeiro volume do Dicionário histórico de filosofia, publicado em 1971, deixaria clara a concentração hermenêutica do 
projeto. Gumbrecht expõe que anteriormente à publicação do Dicionário, especificamente em um texto de 1964, no qual Ritter lançou as suas bases teóricas, o autor demonstrava-se aberto para um diálogo com as proposições teóricas de Hans Blumenberg. Entretanto, como as reflexões de Blumenberg sobre o não conceitual se abriam para o que estava além da linguagem, as suas propostas de análise das metáforas e os usos metafóricos foram programaticamente excluídos do projeto. Essa renúncia fundamentou-se no reconhecimento por parte de Ritter de que a análise das metáforas requereria mais do que as pesquisas poderiam alcançar, sendo imprudente "contentar-se com improvisações precárias" (GUMBRECHT, 2012, p. 28).

Gumbrecht expõe que as incorporações das metáforas eram, de fato, uma ameaça ao projeto do dicionário. Ritter não poderia incorporá-las no futuro refinando o “instrumental analítico”, como fica evidente em sua justificativa no prefácio, já que “[...] as metáforas e o indizível se fecham a quaisquer métodos interpretativos normalizadores" (GUMBRECHT, 2012, p. 30). Gumbrecht cita um ensaio de Blumenberg que precedeu em três anos a obra Paradigmas para um Metaforologia, com o objetivo de demonstrar como as metáforas são uma esfera "anterior ao conceito", que em sua dinâmica concreta "é mais plástica, mais sensível ao inexprimível, menos dominada por formas fixadas pela tradição" (BLUMENBERG, apud GUMBRECHT, 2012, p. 29). Gumbrecht ainda expõe como Blumenberg define sua concepção de “metáfora absoluta” relacionando-a às dimensões inexprimíveis da realidade que resistem à logicidade. Cita o filósofo novamente para demonstrar como a historicidade das metáforas é mais estruturante que as dos conceitos, "pois a mudança histórica de uma metáfora põe em evidência a metacinética dos horizontes e modos de ver históricos, em cujo âmbito os conceitos sofrem mudanças" (BLUMENBERG apud GUMBRECHT, 2012, p. 30).

Segundo Gumbrecht, os Conceitos históricos básicos também não se abriram para as metáforas devido à sua relação ambígua com a história social, tida como horizonte de referência extralinguístico último. Perante essa exclusão das metáforas, ou seja, de dimensões da realidade que resistem à atribuição de sentido, o autor expõe a necessidade dos intelectuais contemporâneos ligados à tradição da história dos conceitos incorporarem essa demanda. Essa reivindicação enquadra-se dentro dos projetos 
gestados por Gumbrecht contemporaneamente, que se propõe a demonstrar como as experiências estéticas ou experiências de intensidade são realidades que afetam materialmente o corpo humano e não podem ser reduzidas a operações hermenêuticas. Gumbrecht tem explorado como as ciências humanas podem contribuir para uma complexificação da experiência humana de mundo ao se abrirem para a evocação de presenças ou Stimmungen, ou seja, de experiências de intensidade nas quais a dualidade corpo e mente seja suspendida (GUMBRECHT, 2010; GUMBRECHT, 2012). Em face dessa perspectiva que confere centralidade ao não conceitual, o autor expõe a importância dos intelectuais ligados à tradição da história dos conceitos retomarem o desafio da abertura para as metáforas:

Certamente, histórias dos conceitos continuarão a ser escritas no futuro, mas não com as mesmas esperanças e o mesmo entusiasmo que tinham um quarto de século atrás. Em compensação, cresceram a fascinação e o interesse acadêmico por realidades que se presentificam, mas não são conceitualmente apreensíveis pela linguagem. A metaforologia ressurge, hoje, entre as possibilidades analíticas e filosóficas de nos abrirmos para essa dimensão. Nela, a tradição do movimento da história dos conceitos poderia, como potencial intelectual, manter-se presente e, ao mesmo tempo, chegar ao fim. (GUMBRECHT, 2012, p. 59)

Elías Palti chega a conclusões semelhantes às de Gumbrecht. Perante os impasses teóricos vigentes nos escritos de Koselleck, o autor expõe: "Com efeito, o tempo, as contingências, já não são, como Koselleck postulou, alguma coisa externa que vem à história intelectual (História social)" (PALTI, 2010, p. 208). As inconsistências teóricas que davam sustentação à história dos conceitos trazem a demanda da problematização dos motivos subjacentes às mudanças conceituais. Esses motivos não são, segundo Palti, de ordem extralinguística. Para Palti, eles se relacionam com dimensões da realidade que afetam a linguagem, mas não podem ser plenamente representadas por ela. Nesse sentido, o autor reivindica a importância de uma teoria da não conceitualidade:

Com efeito, aquilo que excede o mundo da vida, e que desloca os horizontes de compreensão estabelecidos por ele, já não é mais percebido como situado fora do campo simbólico; isso não nos remete para algo externo a linguagem. A expansão do campo simbólico que aquelas filosofias produzem torna explícito os pontos de contato através dos quais tal dimensão de facticidade que previne o fechamento lógico do campo simbólico é introduzida no mesmo, constituindo um elemento 
inerente. O objeto da teoria da não-conceitualidade - o que as metáforas, mitos, e outras formas não conceituais de figurações simbólicas da realidade possibilitam-nos aproximar - não está fora da linguagem (alguma coisa que introduz novos conceitos ou definições de fora da história intelectual), nem é mesmo uma instância interna (o que resultaria na mera recomposição de elementos disponíveis dentro daquele mesmo horizonte), mas um tipo de "constitutivo externo", um elemento que pertence ao universo da realidade simbólica, no entanto, não tem um valor positivo dentro desse sistema, indicando seu ponto de fratura inerente, um espaço vazio que demanda ser preenchido com sentido por meio de procedimentos figurativos, sem nunca ser completamente esgotado. (PALTI, 2010, p. 210)

Seguindo Blumenberg, Palti expõe que toda metáfora é uma metáfora de si mesma e sua precariedade última reside na impossibilidade da sua autorrepresentação. Sendo assim, as metáforas não podem ser compreendidas como meros ornamentos da linguagem, pois provocam o distúrbio do que está sedimentado enquanto sentido; elas remetem ao que é conceitualmente inapreensível. As metáforas apontam para a radical "contingência e irracionalidade das suas fundações" ao colocar a "esfera simbólica em contato com o que a excede e não pode ser localizado além dela - pois, de fato a habita: o vazio que é constitutivo dela" (PALTI, 2010, p. 207). Ora, a própria “inexpressibilidade” das metáforas "as fazem insustentáveis, já que elas frustram todas as tentativas de controle simbólico". Dessa forma, “toda metáfora não é nada além de uma metáfora da sua própria impossibilidade, da sua falha última, que força a linguagem dobrar sobre si mesma" (PALTI, 2010, p. 208). Ao demonstrar a partir das predicações de Blumenberg como as metáforas subjazem às mudanças conceituais e não podem ser esgotadas através de métodos hermenêuticos, Palti diferencia os princípios caros à história dos conceitos da forma como definida por Koselleck de uma metaforologia. Segundo o autor, a história dos conceitos “[...] procura compreender as conexões significativas que articulam as mudanças em uma unidade de sentido, a teoria da não conceitualidade, por outro lado, tenta reconstruir os momentos críticos quando essas conexões foram postas em questão" (PALTI, 2010, p. 207).

Portanto, podemos perceber como Gumbrecht e Palti, mesmo reconhecendo a importância do legado da história dos conceitos, não deixaram de apontar seus limites. Ambos convergem ao encontrarem nos textos de Blumenberg, dedicados a uma teoria da 
não conceitualidade, a possibilidade de dinamização contemporânea do legado da história dos conceitos. Deve-se destacar que Gumbrecht enfatiza que Koselleck também fez incursões historiográficas em dimensões não conceituais. O autor refere-se ao texto Terror e Sonho, presente na coletânea Futuro Passado. Gumbrecht ainda aponta como esse texto gerou um desconforto em meio aos colegas alemães quando o mesmo foi apresentado no ano de 1970. Por sua vez, Palti concentrou suas análises unicamente nas reflexões de Koselleck ligadas diretamente aos Conceitos históricos básicos. Dessa forma, em consonância com as perspectivas de Gumbrecht e Palti, podemos expandir a reflexão explorando como Koselleck em seu projeto intelectual articulou a análise das "metáforas espaciais".

A teoria da modernização de Koselleck e a análise das "metáforas espaciais": um diálogo possível com Blumenberg?

Podemos considerar que a teoria da modernização de Reinhart Koselleck é de relativo conhecimento em meio ao público acadêmico brasileiro dedicado aos estudos teórico-historiográficos, o que em grande medida se deve às traduções de obras fundamentais do autor para a língua portuguesa. Em especial, faço referência às recentes traduções dos livros Crítica e Crise (1999), Futuro Passado (2006), O Conceito de História (2013) e Estratos do Tempo (2014). Apesar do grande valor das referidas traduções, o nosso objetivo de analisar a importância conferida por Koselleck às "metáforas espaciais" e sua articulação com a teoria da modernização, nos conduz à apreciação de alguns artigos presentes no livro The Practice of Conceptual History (2002), devido à intensidade com que o autor aborda a questão.

Koselleck desenvolve no primeiro capítulo, On the Need for Theory in the Discipline of History, uma série de argumentos com o objetivo de demonstrar como a historiografia potencialmente pode dialogar de forma mais intensa com outros campos científicos mediante a sua abertura para hipóteses teóricas mais abrangentes. A necessidade de intensificação dos estudos teóricos torna-se premente perante o fato do conceito de "história" poder ser tanto mobilizado como uma categoria analítica quanto como um conceito "meta-histórico": "Nosso conceito de história permanece ambivalente: em 
referência a um objeto, história torna-se uma categoria histórica; sem um objeto, permanece uma quantidade metahistórica" (KOSELLECK, 2002, p. 4). Essa ambivalência semântica remonta-se ao processo de temporalização do conceito processada no século XVIII, quando a "história em si" e a "filosofia da história" tinham significados idênticos. Esse componente meta-histórico teria sido absorvido pelo conceito de "historicidade".

Entretanto, apesar de considerar que o conceito de historicidade, cujo ápice qualitativo foi elaborado por Heidegger, superou o "permanente processo de relativização pelo qual o historicismo foi reprovado", ao "absolutizar a relatividade", Koselleck expõe o enredamento do mesmo a propensões meta-históricas, ao apontar para as condições de possibilidades da mobilidade e da mutabilidade ao invés do movimento concreto e da mudança concreta (KOSELLECK, 2002, p. 2). Nesse sentido, o autor escreve: "É suposto que a Historicidade delineia tanto as condições de possibilidade de histórias (Geschichten), bem como o lugar que a pesquisa histórica ocupa em seu seio" (KOSELLECK, 2002, p. 4). Sendo assim, em face à ambivalência semântica inerente aos conceitos de história e historicidade, Koselleck expõe a centralidade das reflexões teóricas que possibilitam a delimitação de periodizações que tornam possível a definição de objetos históricos:

[...] a história concebida como ubíqua pode apenas existir como uma disciplina se ela desenvolver uma teoria de periodização; sem tal teoria, a história perde a si mesma em um questionamento ilimitado de tudo. Assumo que categorias metahistóricas e históricas serão forçadas a convergir na questão da periodização. (KOSELLECK, 2012, p. 4)

A argumentação de Koselleck reflete o sucesso alcançado pela sua teoria da modernização, que serviu de pano de fundo para as pesquisas produzidas no âmbito dos Conceitos históricos básicos. Para Koselleck, o sucesso da história enquanto disciplina reside na possibilidade da compreensão processual do tempo histórico mediante o distanciamento teórico, que possibilita a ordenação do passado. A partir da mobilização da teoria, o tempo natural, expresso metaforicamente, pode ser compreendido e explicado historicamente. Para Koselleck, a capacidade de tradução das metáforas que expressam o tempo natural foi decisiva para o sucesso do processo de temporalização da história e disciplinarização da historiografia. 
Nós vivemos por expressões metafóricas naturais, e não estamos aptos a escapar delas, pela simples razão que o tempo não é manifesto (anschaulich) e não pode ser intuído (anschaulich gemacht werden). Todas categorias históricas, incluindo progresso, que é a primeira categoria especificamente moderna de tempo histórico, são expressões espaciais por origem, e nossa disciplina prospera porque elas podem ser traduzidas. "História" originalmente também conteve um sentido espacial, que se tornou temporalizado a um tal nível que nós referimos à duplicação da "história estrutural" se desejarmos (re-)introduzir estatísticas, duração, ou extensão de longo prazo em nosso conceito de história.

Ao contrário de outros modos de estudo, a história como uma disciplina vive por expressões metafóricas. Esta é a nossa premissa antropológica, como foi para tudo que deve ser articulado em termos temporais e é forçado a apoiar-se na base sensória da intuição natural. A impossibilidade de intuir o tempo em seu estado bruto guia-nos diretamente em dificuldades metodológicas concernentes se afirmações significativas sobre a teoria da periodização pode ser feita em última instância. Um perigo específico esconde-se atrás das dificuldades: a saber, que a nossa pesquisa empírica aceita ingenuamente as metáforas como elas vêm a nós. Devemos confiar nos empréstimos dos usos da linguagem cotidiana ou outras disciplinas. A terminologia emprestada e a necessidade de usar expressões metafóricas - porque o tempo claramente não manifesta a si mesmo - requere constantes garantias metodológicas que referem à teoria do tempo histórico. Isso guia-nos novamente à questão da “duração". (KOSELLECK, 2002, p. 7) [Grifos meus]

Koselleck expõe que a relação humana com o tempo é mediada pelas metáforas, no entanto, contrariamente a Blumenberg, o historiador alemão afirma que o sucesso da historiografia reside justamente na possibilidade de tradução do sentido das mesmas. Isso se torna possível mediante a operacionalização de uma teoria do tempo histórico, capaz de estabelecer periodizações que organizem a dinâmica das durações sedimentadas na linguagem. A hipótese central do dicionário parte da predicação de que apesar do contínuo uso das palavras, a significação da "linguagem político-social tem mudado desde o século dezoito", quando uma nova experiência de tempo histórico começou a ser articulada. Nesse sentido, o autor expõe: “Coeficientes de mudança e aceleração transformam campos de sentido antigos e, portanto, experiências políticas e sociais" (KOSELLECK, 2002, p. 5). Essas transformações puderam ser traduzidas através da utilização de um método histórico, que leva em consideração uma "estrutura de referência que tem sido clarificada teoricamente", isto é, o período de "transformação do uso pré-moderno da linguagem ao nosso", denominado Sattelzeit (KOSELLECK, 2002, p. 5). 
A antecipação teórica da periodização do Sattelzeit, que teria se processado por volta de 1750 e 1850, impor-se-ia enquanto um instrumento heurístico viabilizador da verificação da "desnaturalização" de uma "antiga experiência do tempo" passível de ser constatada a partir da análise dos usos de conceitos fundamentais. Em tensão com o processo de modernização da experiência teria sido desencadeado o "lento declínio do conteúdo semântico aristotélico, que se referia a um natural, repetível e, portanto, estático tempo histórico", passível de ser compreendido como o "indicador negativo de um movimento que pode ser descrito como o início da modernidade" (KOSELLECK, 2002, p. 5). Para Koselleck, o campo semântico aristotélico coexistiu enredado à demanda por aceleração e movimento, que impulsionou o esvaziamento das significações determinantes para a imutabilidade. Nesse sentido, o processo de modernização deu-se envolvido em tensões semânticas provocadas pela radicalização da coexistência da contemporaneidade do não contemporâneo. Entretanto, a lógica vanguardista do processo de modernização sedimentada em conceitos como "história”, "progresso" e "revolução" teria dado a orientação ao movimento.

Se assumirmos que o tempo histórico permanece envolvido no tempo natural sem estar inteiramente contido nele; ou, colocado de forma diferente, que enquanto o tempo do dia pode ser relevante para decisões políticas, conexões históricas não podem ser medidas com um relógio; ou colocado de forma diferente novamente, que a revolução das estrelas não é mais (ou ainda não novamente) relevante para o tempo histórico, dessa forma, nós devemos encontrar categorias históricas que são adequadas aos eventos históricos e processos. (KOSELLECK, 2002, p. 6)

Para Koselleck, a experiência da história é mediada por expressões metafóricas, premissa antropológica que impõe a necessidade de confiarmos na "base sensória da nossa intuição natural”. Entretanto, o processo de modernização da experiência possibilitou que a emergência de conceitos históricos de movimento esvaziasse o sentido natural, biológico e espacial das metáforas. Koselleck expõe que esse processo se deu enredado em descontinuidades, ou seja, pressupõe a tensa coexistência da simultaneidade do não simultâneo. Todavia, o processo de aceleração da história impulsionado por conceitos de movimento capazes de orientar as ações com finalidades futuras previamente planejadas foi decisivo para o deslocamento da centralidade da 
“base sensória da intuição natural”. Perante a centralidade da dinâmica dos conceitos de movimento, as afirmações de Koselleck de que a "história como disciplina vive por expressões metafóricas", sendo as mesmas "nossa premissa antropológica”, pois "tudo que deve ser articulado em termos temporais é forçado a confiar na base sensória da intuição natural” é deixada imediatamente de lado. Para Koselleck, o repertório de conceitos e categorias modernas são garantias da transmissão de experiências significativas, asseguram a orientação da ação humana e a reprodução dos objetos científicos. Sendo assim, apesar de Koselleck reivindicar uma centralidade antropológica para as metáforas, ele imediatamente recua ao fazer esse gesto, ao subsumir a "base sensória da intuição natural” à lógica de produção de sentido moderna. Portanto, para o historiador alemão, se por um lado as metáforas são tidas como uma dimensão estruturante da linguagem, que nos aproxima de nossas premissas antropológicas, por outro, essas premissas são destituídas de dignidade ao sucumbirem à lógica de reprodução de sentido moderna no processo de temporalização da experiência.

No texto "Progress" and "Decline" Koselleck demonstra a sua indecisão teórica quanto à centralidade das metáforas:

Em princípio, conceitos históricos genuinamente, aqueles que têm a ver com o tempo histórico, não existem. É sempre uma questão de metáforas. No que se segue, teremos então que ter atenção ao conteúdo metafórico de nossos conceitos para que sejamos aptos a avaliar o poder de sua expressividade histórica.

Em princípio, eu simplesmente pressupunha que progresso é um conceito moderno (neuzeitlich). Agora minha tese histórico-conceitual específica é a seguinte. Progresso tornou-se um conceito moderno quando perdeu ou esqueceu sua origem natural que significava percorrer o espaço. A referência figurativa desvaneceu. Desde por volta de 1800, progresso tornou-se um conceito histórico genuinamente, enquanto "declínio" e "decadência" não foram capazes de perder seu significado de origem natural e biológico da mesma forma. (KOSELLECK, 2002, p. 221)

Ora, primeiramente Koselleck afirma que as metáforas são a dimensão mais estruturante da linguagem, que são responsáveis por nos ligar à "base sensória da intuição natural", ou seja, são premissas antropológicas anteriores às nossas relações com os conceitos, para depois afirmar que o conceito moderno de movimento 
"progresso" deslocou completamente essas pressuposições. De forma semelhante, o mesmo pressuposto é mobilizado por Koselleck em suas análises sobre o conceito de Revolução. O historiador alemão considera que estratos semânticos de outros períodos históricos vigoraram e desempenharam função importante no processo de temporalização do conceito no período do Sattelzeit. Contudo, Koselleck afirma que os substratos metafóricos associados a esse conceito, que se remetem a experiências de tempo histórico circulares, foram esvaziados e instrumentalizados pela sua dinâmica moderna. Em alguma medida, Koselleck expõe que a continuidade do movimento e o seu caráter circular sedimentados na performance metafórica do termo Revolução desempenharam função importante para que o conceito na modernidade fosse experimentado enquanto uma espiral, que pressupunha a coexistência e alternância de contextos de avanço e retrocesso. Todavia, o movimento acelerado em direção ao futuro não era ameaçado pela performance metafórica que subjaz o emprego do conceito. Para Koselleck, os estratos metafóricos em vigor no conceito poderiam tencionar com a atribuição de sentido moderna e possibilitar que o movimento tomasse outra forma. Entretanto, eles não poderiam suspender a atribuição de sentido. Não eram ameaças concretas ao movimento acelerado (KOSELLECK, 2002, pp. 148-153; KOSELLECK, 2012, pp. 161-170). Portanto, em última instância, para Koselleck, a dinâmica semântica moderna possibilita o esgotamento do sentido das metáforas e consequentemente a instrumentalização das mesmas como auxiliares nos projetos dedicados à escrita da história conceitual. Com efeito, podemos perceber o quão distante a análise das metáforas em Koselleck está das proposições de Hans Blumenberg.

O terceiro capítulo de The Practice of Conceptual History trata-se de uma introdução ao livro Trópicos do Discurso de Hayden White, autor que, por sua vez, introduziu a coletânea em questão. O historiador alemão chega a comparar o trabalho de Blumenberg com o de White, ao considerar que ambos procedem de forma semelhante ao considerarem que "o poder linguístico das metáforas revela a experiência e precede todas as enunciações" (KOSELLECK, 2012, p. 39). Como vimos, Koselleck também reivindicou centralidade às metáforas como uma dimensão estruturante, porém, o autor não citou Blumenberg relacionando-o à sua análise. De forma alternativa a Koselleck, 
Blumenberg não predicou que as significações e experiências contidas nas metáforas poderiam ser controladas e traduzidas por um método. Ou mesmo que a modernização da experiência suplantou a capacidade subversiva das metáforas de suspenderem a transmissão de sentido. Blumenberg coloca a questão de como a linguagem pode representar o inexprimível através das metáforas, que são um “distúrbio" a qualquer possibilidade de harmonização das significações (BLUMENBERG, 1997: 82). Apesar de considerar que as metáforas são fundamentais para a formação dos conceitos, o autor expõe que elas são um "fio condutor" para o "mundo da vida", devendo ser compreendidas dentro de um "amplo horizonte de uma teoria da não conceitualidade" (BLUMENBERG, 1997: 82). Dessa maneira, o autor escreve:

[...] a metaforologia que não queira restringir a metáfora à função de auxiliar para a construção do conceito, senão considera-la como fio condutor em face do mundo da vida, não será suficientemente se não a inserirmos no horizonte mais amplo de uma teoria da não conceitualidade. A possibilidade de falar do prado risonho é, no entanto, não só uma sugestão poética; a evidência estética precisa que todos a tenham visto sem que pudessem dizê-la. Portanto não é uma invenção poética. Ela se oferece nas relações do mundo da vida. Não só o dito como também o indizível pode se fazer temático se, de antemão, renunciamos a provincializá-los em estados de coisas e em fatos místicos. O que quero dizer talvez se torne mais claro pela antinomia que, na cultura contemporânea do jargão teórico e sobretudo do mal-estar por não poder alcançar o seu padrão, se configura como uma diferença verbal definitiva. (BLUMENBERG, 2013, p. 167)

Blumenberg parte da metáfora clássica de Quintiliano de que o prado ri (pratum ridet) para demonstrar como as metáforas são tanto um obstáculo à transmissão de sentido unívoco, quanto uma conexão dos homens com o mundo da vida. Com relação ao desafio colocado pelas metáforas ao sentido pleno, o autor utiliza o exemplo do "prado risonho" para demonstrar como o predicado é "contrário a toda expectativa de informações possíveis sobre o prado" (BLUMENBERG, 2013, p. 162). No entanto, esta insuficiência de estabelecer sentidos unívocos é contrabalanceada pelo potencial da metáfora representar o inexprimível. Blumenberg considera que tal representação não é um produto da subjetividade do poeta que encontra os contornos da face na espacialidade, já que a metáfora emerge da atribuição do inventário da vida humana no 
mundo ao prado (BLUMENBERG, 1997, p. 82-83). A possibilidade de se falar sobre o "prado risonho" reside no fato de várias pessoas o terem contemplado sem terem sido hábeis de realizarem tal enunciação (BLUMENBERG, 1997, p. 88).

Para além de limitarem-se ao âmbito da transmissão do sentido como os conceitos, as metáforas possibilitam a articulação do indizível e do possível às relações que se processam no mundo da vida. Para Blumenberg, "[...] a metáfora é um meio estético, pois tanto é natural da esfera de origem do conceito como continuamente fazse responsável pela insuficiência do conceito e pelos limites da sua operação" (BLUMENBERG, 2013, p. 67). Blumenberg não concebe a metaforologia como uma “disciplina estética”, pois a mesma "considera a relação entre conceito e metáfora como genética e funcional”, no entanto, o seu objetivo é "descrever e esclarecer como a metáfora penetra no contexto estético, ou melhor, como a estética, em seu conjunto, deriva do substrato metafórico e mítico" (BLUMENBERG, 2012, p. 67).

A carência da linguagem torna as metáforas imprescindíveis. No entanto, paradoxalmente, a performance das metáforas evidencia a insuficiência delas em representar as coisas e mesmo a resistência à atribuição de sentido ao instaurar a possibilidade da fruição estética. Dessa forma, a metaforologia não se restringe à “subestrutura ou o campo da construção conceitual”. A abertura para as metáforas possibilita explorar o "instrumentário construtivo do mundo da vida" em suas dimensões não passíveis de significação, “onde as concepções pré-filosóficas resistem à sua dissolução na conceitualidade teórica, em que também, e especialmente, a metáfora pode assumir sua função absoluta e que não se pode traduzir arbitrariamente em um discurso apropriado ou substituir-se por este" (BLUMENBERG, 2013, pp. 173-174).

Em tensão com as proposições de Blumenberg, Koselleck centrou seus esforços analíticos na articulação e rearticulação da experiência histórica nos conceitos de movimento, por sua vez, decisivos para o desencadeamento e consolidação do processo de modernização. Como explorado anteriormente, Gumbrecht e Palti compreendem como o caráter subversivo do projeto de Blumenberg era corrosivo perante as pretensões teóricas da história dos conceitos. No entanto, como enfatizado aqui, Koselleck também se abriu à sua maneira para a análise das metáforas. Podemos 
perceber como o historiador alemão propôs-se a mapear os horizontes semânticos que emergiram a partir da performance das "metáforas espaciais". Nesse sentido, podemos compreender como Koselleck procurou instrumentalizar as metáforas em sua teoria da modernização, que se lançou ao desafio de esgotar os horizontes semânticos dos conceitos de movimento. Em contrapartida, Blumenberg seguiu radicalmente outro caminho ao encontrar nas metáforas a abertura para o não conceitual, o indizível, ou seja, aquelas dimensões do mundo da vida que instauram a possibilidade da fruição estética, desafiam e até mesmo suspendem a possibilidade da transmissão de experiências passíveis de significação.

Como exploramos acima, as contribuições de Koselleck para a historiografia são incontornáveis, principalmente no que diz respeito à compreensão das múltiplas temporalidades sincrônicas que constituem a experiência da história. Todavia, a proposição de Blumenberg de que precisamos ir além do desafio de esgotar os sentidos dos múltiplos presentes e passados apresenta-se como fundamental, tendo em vista o afã cientificista da nossa contemporaneidade, que nutre a expectativa de disciplinar toda a nossa experiência de mundo (BLUMENBERG, 1997, p. 88-89). O autor considera que a abertura para o indizível, para aquelas dimensões do mundo da vida que não são passíveis de serem plenamente explicadas, constituem-se enquanto desafios às garantias do presente (BLUMENBERG, 1997, p. 86). Dessa forma, mais do que reconhecer os horizontes de sentido dos presentes e dos passados que constituem nossa experiência da historicidade, Blumenberg coloca o desafio da abertura para experiências de mundo indizíveis que foram soterradas, mas que são passíveis de serem experienciadas e serem representadas pelas metáforas pelo fato das mesmas estarem em relação com o mundo da vida.

Em consonância com os questionamentos e proposições de Blumenberg, intensificados por Gumbrecht e Palti, podemos perceber que estudos teóricohistoriográficos recentes têm enfatizado a necessidade de uma atenção renovada ao não conceitual, à sentimentalidade e à presença do passado, explorando os seus potenciais disruptivos e tensões com a demanda por cristalização de sentidos (PHILIPS, 1997, 2013; BEVERNAGE, 2012, 2018; RUNIA, 2014; ARAUJO, 2013; ARAUJO; RANGEL, 2015; 
KLEINBERG, 2017; KLEINBERG; RAMOS, 2017; RAMOS 2013, 2018). O desafio em questão, sistematizado de forma distinta por autores de diversos países, é a necessidade do descongelamento de aberturas para experiências da historicidade que não se limitem aos horizontes de sentido normalizados nos projetos de modernização vitoriosos no Ocidente.

\section{Referências}

ARAUJO, Valdei Lopes de. A experiência do tempo: conceitos e narrativas na formação nacional brasileira (1813-1845). São Paulo: Hucitec, 2008a.

ARAUJO, Valdei Lopes de. História da historiografia como analítica da historicidade. História da historiografia, Ouro Preto, n. 12, p. 34-44, ago., 2013.

ARAUJO, Valdei Lopes de. História dos conceitos: problemas e desafios para uma releitura da modernidade Ibérica. Almanack Braziliense (Online), v. 7, p. 47-55, 2008b.

ARAUJO, Valdei Lopes de. Observando a observação: sobre a descoberta do clima histórico e a emergência do cronótopo historicista, c. 1820. In: CARVALHO, José Murilo; CAMPOS, Adriana Pereira. (Orgs.). Perspectivas da cidadania no Brasil Império. 1ed. Rio de Janeiro: Civilização Brasileira, 2011a. p. 281-304.

ARAUJO, Valdei Lopes de. Para além da autoconsciência moderna: a historiografia de Hans Ulrich Gumbrecht. Varia História, v. 22, p. 314-328, 2006.

ARAUJO, Valdei Lopes de. Sobre a permanência da expressão história magistral vitae no século XIX brasileiro. In: NICOLAZZI, Fernando; MOLLO, Helena Miranda; ARAUJO, Valdei Lopes de. Aprender com a história? o passado e o presente de uma questão. Rio de Janeiro: Fundação Getúlio Vargas, 2011b. p. 131-147.

ARAUJO, Valdei Lopes de; RAMOS, André da Silva. A emergência de um ponto de vista cosmopolita: a experiência da história de Portugal na Universal History. Almanack, v. 10, p. 479-491, 2015. 
ARAUJO, Valdei Lopes de; RAMOS, André da Silva. Disputas pela história contemporânea de Portugal: a polêmica político-historiográfica entre José Agostinho de Macedo e Hipólito da Costa. Revista Maracanan, v. 19, p. 197-215, 2018.

ARAUJO, Valdei Lopes de; RANGEL, Marcelo de Mello. Apresentação: teoria da história e história da historiografia: do giro-linguístico ao giro ético-político. História da historiografia, Ouro Preto, n. 17, p. 318-332, abr. 2015.

BEVERNAGE, Berber; LORENZ, Chris. Negotiating the borders between present, past and future. Göttingen: Vandenhoeck \& Ruprecht, 2013.

BEVERNAGE, Berber. History, memory, and state-sponsored violence: time and justice. New York: Routledge, 2012.

BEVERNAGE, Berber. História, memória e violência de Estado: tempo e justiça. Tradução: André Ramos; Guilherme Bianchi. Serra: Editora Milfontes/Mariana: SBTHH, 2018.

BLUMENBERG, Hans. Shipwreck with spectator: paradigm of a metaphor for existence. Massachusetts: Massachusetts Institute of Technology, 1997.

BLUMENBERG, Hans. Teoria da não conceitualidade. Belo Horizonte: Editora UFMG, 2013.

FERES JR; JASMIN, Marcelo Gantus. História dos conceitos: debates e perspectivas. Rio de Janeiro: Editora Puc-Rio: Editora Loyola: IUPERJ, 2006.

GOSH, Ranjan; KLEINBERG, Ethan (Orgs.). Presence: philosophy, history, and cultural theory for the twenty-first century. Ithaca, New York.: Cornell University Press, 2013.

GUMBRECHT, Hans Ulrich. Atmosphere, mood, stimmung: on a hidden potential of literature. Califórnia: Stanford University Press, 2012.

GUMBRECHT, Hans Ulrich. Pirâmides do Espírito. Sobre a rápida ascensão, as dimensões invisíveis e o súbito esmorecimento da história dos conceitos. Graciosidade e estagnação. Rio de Janeiro: Contraponto; Rio de Janeiro: Puc-Rio, 2012. p. 15-60.

GUMBRECHT, Hans Ulrich. Produção de presença: o que o sentido não consegue transmitir. Rio de Janeiro: Contraponto; Rio de Janeiro: Puc-Rio, 2010.

JORDHEIM, Helge. Against Periodization: Koselleck's theory of Multiple temporalities. History and theory, v. 51, n. 2, p. 151-171, 2012. 
KLEINBERG, Ethan. Back to where we've never been: Heidegger, Levinas and Derrida on tradition and history. History and theory, v. 51, p. 114-135, 2012.

KLEINBERG, Ethan. Haunting history: for a deconstructive approach to the past. Stanford: Stanford University Press, 2017.

KLEINBERG, Ethan; RAMOS, André da Silva. Ethan Kleinberg: theory of history as hauntology. História da historiografia, Ouro Preto, n. 25, p. 212-228, dez. 2017. Entrevista concedida a André da Silva Ramos.

KOSELLECK, Reinhart. The practice of conceptual history: timing history, spacing concepts. California: Stanford University Press, 2002.

KOSELLECK, Reinhart. Revolución como concepto e como metáfora. Sobre la semântica de una palavra en un tiempo enfática. In: KOSELLECK, Reinhart. Historia de conceptos: estudios sobre semântica y pragmática del linguaje político y social. Madrid: Trotta, 2012. p. 161-170.

PALTI, Elías José. Ideas, conceptos e metáforas: La tradición alemana de la historia intelectual y el complejo entramado del linguaje. In: SEBASTIÁN, Javier Fernández y MIGUEL, Gonzalo Capellán (Orgs.). Lenguaje, tempo y modernidade: Ensayos de historia conceptual. Chile: Globo Editores, 2011.

PALTI, Elías José. From ideas to concepts to metaphors: the german tradition of intelectual history and the complex fabric of language. History and theory, v. 49, p. 194211, 2010.

PHILIPS, Mark Salber. On historical distance. New Haven \& London: Yale University Press, 2013.

PHILIPS, Mark Salber. Society and sentiment: genres of historical writing in britain, 17401820. Princeton University Press, 1997.

RAMOS, André da Silva. Machado de Assis e a experiencia da história: climas e espectralidade. 2018. Tese (Tese em História) - Universidade Federal de Ouro Preto, Mariana, 2018.

RAMOS, André da Silva. Robert Southey e a experiência da história de Portugal: conceitos, linguagens e narrativas cosmopolitas (1795-1829). 2013. Dissertação (Mestrado em História) - Universidade Federal de Ouro Preto, Mariana, 2013. 
RAMOS, André da Silva; RODRIGUES, Thamara de Oliveira. Narrativas sobre a experiência da história contemporânea do império Luso-Brasileiro: Hipólito da Costa e Francisco Solano Constâncio (1808-1810). Revista do instituto histórico e geográfico brasileiro, $n$. 463, p. 13-37, jun. 2014.

RANGEL, Marcelo de Mello. O período regencial e o clima histórico: pessimismo e esperança na poesia de Gonçalves de Magalhães. ArtCultura, Uberlândia, v. 15, n. 26, p. 169-186, jan.-jun. 2013.

RANGEL, Marcelo de Mello. Romantismo, Sattelzeit, melancolia e 'clima histórico' (Stimmung). Revista expedições: teoria da história \& historiografia, v. 5, n. 2, p. 53-62, juldez., 2014.

RANGEL, Marcelo de Mello. Poesia, história e economia política nos suspiros poéticos e saudades e na revista Niterói: os primeiros românticos e a civilização do império do Brasil. 2011. Tese (Doutorado em história social) - Pontificia Universidade Católica - Rio, Rio de Janeiro, 2011.

RODRIGUES, Thamara de Oliveira. A independência de Portugal: história, progresso e decadência na obra de Francisco Solano Constâncio. 2014. Dissertação (Mestrado em História) - Universidade Federal de Ouro Preto, Mariana, 2014.

RUNIA, Eelco. Moved by the Past: discontinuity and historical mutation. New York: Columbia University Press, 2014.

SEBASTIÁN, Javier Fernández. Hacia una historia atlántica de los conceptos políticos. In: SEBASTIÁN, Javier Fernández. (Dir.). Diccionario politico y social del mundo iberoamericano: conceptos políticos en la era de las revoluciones, 1750-1850. Madrid: Fundación Carolina, 2009a. p. 23-45.

SEBASTIÁN, Javier Fernández. Conceptos y metáforas en la política moderna: algunas propuestas para una nueva historia político-intelectual. In: CANAL, Jordi y LUZÓN, Javier Moreno (Orgs.). Historia cultural de la política contemporânea. Madrid: Centro de estudios políticos y constitucionales, 2009b. p. 11-30.

SEBASTIÁN, Javier Fernández. Introducción: tiempos de transición en el atlântico ibérico: conceptos políticos en revolución. In: (Dir.). Diccionario politico y social del mundo iberoamericano: conceptos políticos fundamentales, 1770-1870: [Iberoconceptos - II]: tomo I (civilización). Madrid: Centros de estudos políticos y constitucionales, 2014. p. 2575 . 
Recebido em 12/01/2017 Aprovado em 17/05/2018

Universidade do Estado de Santa Catarina - UDESC Programa de Pós-Graduação em História - PPGH Revista Tempo e Argumento Volume 11 - Número 26 - Ano 2019 tempoeargumento@gmail.com 